\section{PTU-039 COLONOSCOPIC POLYP DETECTION RATE IS STABLE THROUGHOUT THE WORKDAY INCLUDING IN EVENING COLONOSCOPY SESSIONS}

doi:10.1136/gutjnl-2013-304907.131

1,"D Thurtle, ${ }^{2} \mathrm{M}$ Pullinger, ${ }^{2} \mathrm{~J}$ Tsigarides, ${ }^{2} \mathrm{Mcintosh},{ }^{2} \mathrm{C}$ Steytler, ${ }^{1,2} \mathrm{~L} \mathrm{~L}$ Beales. 'Gastroenterology, Norfolk and Norwich University Hospital; ${ }^{2}$ Norwich Medical School, Norwich, UK

Introduction Polyp detection rate (PDR) is an accepted measure of quality of colonoscopy. Several factors may influence PDR including time of procedure and rank of colonoscopy within a session. Our unit provides evening colonoscopy lists (6-9 pm) to meet high demand and improve patient convenience, but it is unknown if colonoscopy performance declines in the evening. We have evaluated PDR by endoscopy session with particular reference to the evening session.

Methods Data were collected retrospectively for all NHS outpatient colonoscopies performed at Norfolk and Norwich University Hospital in 2011. Timing, demographics, staffing, indication and findings of colonoscopy were recorded. Descriptive statistics were calculated and statistical analysis was performed using multivariate regression. PDR was defined as the detection of one or more polyps at colonoscopy.

Results Data from 2576 colonoscopies were included: 1163 (45.1\%) were performed in the morning, 1123 (43.6\%) in the afternoon and $290(11.3 \%)$ in the evening. Unadjusted PDR in the morning, afternoon and evening session were $46.4 \%, 35.9 \%$ and $37.2 \%$ respectively. Mean age was lower in the evening sessions (58.15) compared to morning (64.68) and afternoon (62.29).

Factors associated with polyp detection were assessed by multivariable logistic regression. Male gender $(\mathrm{OR}=1.76,95 \% \mathrm{CI} 1.48-$ $2.11, \mathrm{p}<0.001)$, increasing age $(\mathrm{OR}=1.045,95 \% \mathrm{CI}=1.035-1.055$, $\mathrm{p}<0.001)$ and successful caecal intubation $(\mathrm{OR}=2.48$ $95 \% \mathrm{CI}=1.53-4.01, \mathrm{p}<0.001)$ were all significantly associated with higher polyp detection. The indications 'faecal occult blood screening' $(p<0.001)$ and 'polyp surveillance' $(p<0.001)$ were strongly positively associated and 'anaemia' $(p=0.01)$ negatively associated with PDR.

Following standardisation of covariates (including endoscopists), there was no significant difference in PDR between sessions. With the morning as the reference value, the odds ratio for polyp detection in the afternoon and evening were $0.93(95 \% \mathrm{CI}=0.72-1.18)$ and $1.15(95 \% \mathrm{CI}=0.82-1.61)$ respectively. $\mathrm{PDR}$ was not shown to be affected by rank of colonoscopy within list $(p=0.904)$, sedation dose, trainee involvement or endoscopy room.

Conclusion Time of day was not shown to affect polyp detection rate in our clinical practise. Evening colonoscopy had equivalent efficacy and seems to be a useful and effective tool in meeting increasing demands for endoscopy. Standardisation was shown to have a considerable effect as demographics, indication and endoscopist varied substantially between sessions, Evening sessions, outside of standard working hours, were popular with a younger population. Consistent with previous studies, caecal intubation is an important marker of the quality of colonoscopy.

Disclosure of Interest None Declared

\section{PTU-040 STUDY OF QUALITY AND EFFICACY OF BOWEL PREPARATION FOR COLONOSCOPY}

doi:10.1136/gutjnl-2013-304907.132

1."D S Chilkunda, ${ }^{2}$ S Shah. 'Gastroenterology, Leeds Teaching Hospitals NHS Trust, Leeds; ${ }^{2}$ Gastroenterology, Pinderfields General Hospital, Wakefield, UK
Introduction Effective bowel preparation of $\geq 90 \%$ is a key quality indicator for ensuring good standards of colonoscopy ${ }^{1}$. Good quality bowel preparation improves polyp detection and caecal intubation rates. Various regimens used in Mid-Yorkshire NHS Trust (MYNHT) were assessed in 2008 leading to a change in practise. As a result, Citramag and Senna have been used in split doses since then. Aims of the study were to determine the efficacy of Citramag/Senna, and patient acceptability \& tolerability of this regimen. Performance of this regimen was compared to Kleen Prep and oral Fleet used previously.

Methods We prospectively studied data collected from pre-procedure questionnaires completed by patients between Aug 2010 \& May 2011. Endoscopists scored bowel cleansing according to Boston Bowel Prep Scale (BBPS) for each segment $(0-3)^{2}$, on the basis of guidance images and scoring system provided for the duration of the study. Qualitatively, bowel cleansing was graded as A, $\mathrm{B}$ or $\mathrm{C}$, where $\mathrm{A}=$ all segments clean, $\mathrm{B}=$ partially removable stool preventing complete visualisation in at least one segment and $\mathrm{C}=$ solid stool in at least one segment. Exclusion criteria were used to philtre patients who received regimens other than Citramag/ Senna, those with incomplete data and those who had had colonic resection.

Results A total of 194 questionnaires were received during the study period. Of these, 19 patients were excluded from further analysis on the basis of criteria detailed above. Of the remaining 175 cases assessed, $88 \%$ patients found taste of the preparation acceptable or pleasant. $92.5 \%$ were willing to take the same regime again. $44 \%$ patients had adverse effects of which $77 \%$ were mild. This compared favourably to results of Kleen-Prep (62.9\%) \& Fleet (66.2\%). Abdominal cramp was the commonest side effect. Mean total BBPS score was 16.91 (maximum score possible 18). $93.14 \%$ cases were graded A (qualitative score) implying good efficacy of bowel preparation, compared to $45.1 \%$ for Kleen-Prep and $69 \%$ for Fleet.

Conclusion The split-dose regimen of Citramag/Senna meets the Joint Advisory Group (JAG) recommendation for bowel cleansing with efficacy of $>90 \%$ and is better than other regimens previously used in MYNHT. We also found this to be superior to Kleen-Prep and oral Fleet in terms of patient acceptability and adverse effects. Hence, we recommend continuing with the current regimen, and re-assessing this to ensure ongoing efficacy/ benefit. BBPS should be considered for use as a standard scoring tool for assessing efficacy of bowel preparation. However, further validation is required to demonstrate its applicability in day-to-day endoscopy.

Disclosure of Interest None Declared

\section{REFERENCES}

1. BSG quality and safety indicators for endoscopy. Mar 2007

2. Calderwood A \& Jacobson B. Comprehensive validation of Boston bowel preparation scale. Gastrointestinal Endosc. 2010 October; 72(4): 686-692

\section{PTU-041 DEDICATED GI BLEED SERVICES RESULT IN A SIGNIFICANT DIFFERENCE IN INPATIENT MORTALITY: A SOUTH YORKSHIRE EXPERIENCE}

doi:10.1136/gutjnl-2013-304907.133

${ }^{1} \mathrm{M}$ Kurien, 1,"E F Wong, ${ }^{1} \mathrm{~F}$ Gohar, ${ }^{2} \mathrm{~K} L$ Dear, ${ }^{3} \mathrm{~B}$ Hoeroldt, ${ }^{4} \mathrm{~K}$ Kapur, ${ }^{1} \mathrm{~A} \mathrm{~J}$ Lobo, 'D S Sanders. 'Department of Gastroenterology, Royal Hallamshire Hospital, Sheffield; 2Department of Gastroenterology, Chesterfield Royal Hospital, Chesterfield; ${ }^{3}$ Department of Gastroenterology, Rotherham General Hospital, Rotherham; ${ }^{4}$ Department of Gastroenterology, Barnsley District Hospital, Barnsley, UK

Introduction Acute upper GI bleeding (AUGIB) is a common gastrointestinal problem associated with significant mortality. ${ }^{1}$ Whilst numerous factors have been shown to influence mortality in these 